\title{
Characteristics of Zeta Potential Distribution in Silica Particles
}

\author{
Jinkeun Kim* and Desmond F. Lawler ${ }^{\dagger}$
}

\author{
Korea Water Resources Corporation, Water Resources Academy, Daejeon 305-730, Korea. *E-mail: kjinkeun@kowaco.or.kr \\ ${ }^{\dagger}$ Dept. of Civil, Architectural and Environmental Engineering, The University of Texas at Austin, ECJ 8.6 Austin, TX 78712, USA \\ Received March 15, 2005
}

\begin{abstract}
Most experimental studies available in the literature on filtration are based on observed average zeta potential of particles (usually 10 measurements). However, analyses of data using the average zeta potential alone can lead to misleading and erroneous conclusions about the attachment behavior because of the variation of particle zeta potentials and the heterogeneous distribution of the collector surface charge. To study characteristics of zeta potential, zeta potential distributions (ZPDs) of silica particles under 9 different chemical conditions were investigated. Contrary to many researchers' assumptions, most of the ZPDs of silica particles were broad. The solids concentration removal was better near the isoelectric point (IEP) as many researchers have noticed, thus proper destabilization of particles is very important to achieve better particle removal in particle separation processes. While, the mean zeta potential of silica particles at a given coagulant dose was a function of particle concentration; the amount of needed coagulant for particle destabilization was proportional to the total surface charge area of particles in the suspension.
\end{abstract}

Key Words : Zeta potential distribution (ZPD), Electrophoretic mobility, Particle destabilization

\section{Introduction}

Particle Stability and Potential. Most particles acquire a surface electrical charge when brought into contact with water, and in the range of normal $\mathrm{pH}($ e.g., 5-9), it is usually negative. This charge arises from one or more of four principal mechanisms: direct dissociation or ionization of surface groups, lattice imperfections at the solid surface, isomorphic replacements within the lattice, and preferential adsorption of ions from solution. ${ }^{1,2}$ As the surface charge of particles tends to attract ions of opposite charge (counterions) from the solution, and repel ions of same charge (coions), particles in water are usually stable. ${ }^{3}$

The possibility of a positive or negative surface charge exists depending on the $\mathrm{pH}$ of the solution. At low $\mathrm{pH}$, most particles exhibit a positive charge; as the $\mathrm{pH}$ is raised, a negatively charged surface is formed. At some intermediate $\mathrm{pH}$, known as the point of zero charge (PZC) or isoelectric point (IEP) the net charge of the particles is zero. Since the PZC of most particles is in the acidic $\mathrm{pH}$ region, most particles have negative surface charge under conditions encountered in natural waters. The typical IEP of colloidal silica and quartz sand is around 2.0. ${ }^{4}$

The amount of surface charge on a particle can be expressed as charge density, $\sigma_{p}$, with units of $\mathrm{C} / \mathrm{m}^{2}$. According to the Gouy-Chapman theory, the surface charge density can be related to the potential at the surface as in Equation 1. ${ }^{2}$

$$
\sigma_{p}=\left(8 R_{o} T \varepsilon_{w} c_{o} \times 10^{3}\right)^{1 / 2} \sinh \left(z \Psi_{o} F / 2 R_{o} T\right)
$$

where $R_{o}$ is the molar gas constant, $T$ is Kelvin temperature, $\varepsilon_{w}$ is permittivity in water, $c_{o}$ is the molar concentration of electrolyte, $z$ is the charge number, $\Psi_{o}$ is the surface potential, and $F$ is the Faraday constant. At low potential, Equation 1 can be linearized as Equation 2.

$$
\sigma_{p}=\varepsilon_{w} \kappa \Psi_{o}
$$

where $1 / \kappa$ is Debye length, and it can be simply defined as Equation 3 at $25^{\circ} \mathrm{C}$. ${ }^{4,5}$

$$
\kappa=(3.288 \sqrt{I})
$$

where $I$ is ionic strength of solution.

As particles have electrical charge, the requirement of overall electroneutrality of the interfacial region results in the formation of a diffuse layer of oppositely charged counterions adjacent to the surface. Excess ions of opposite charge accumulate in the interfacial region and form an electric double layer (EDL).

Two models are frequently used to describe the interaction of particles as a function of separation distance. The DebyeHückel approximation is useful when the surface potential is low, and can be expressed as Equation 4, while Equation 5 represents Gouy-Chapman model which is not limited to low values of $\Psi_{o}{ }^{6}$

$$
\begin{aligned}
& \Psi(x)=\Psi_{o} \exp (-\kappa x) \\
& \Psi(x)=\Psi_{o} \frac{a}{r} \exp [-\kappa(r-a)]=\Psi_{o} \frac{a}{a+x} \exp [-\kappa(x)]
\end{aligned}
$$

where $\Psi(x)$ is the potential at the distance $x, a$ is the radius of the spherical particle, $r$ is the distance measured from the center of the particle, and $x$ is the distance measured from the particle surface.

Zeta Potential. The most widely used experimental approach to the study of charged surfaces is through the use of electrokinetic techniques. The electrical potential at the shear plane is defined as the electrokinetic potential, more commonly referred to as the zeta potential, with the symbol $\zeta$.

Zeta potential can be deduced from electrokinetic measurements. Besides having the advantage of being experimentally 
accessible, the zeta potential correlates with particle stability. Highly stable colloidal systems are characterized by high zeta potentials, whereas low zeta potentials indicate less stable systems. ${ }^{7}$ Similarly, deposition of particles on to surfaces is very often controlled by the zeta potential of particles and collectors. The zeta potential of colloids and collector surfaces is commonly used in analyses of colloid attachment in porous media. It is generally accepted that these potentials are useful parameters for prediction of colloid attachment kinetics within the framework based on Derjaguin, Landau, Verwey and Overbeek (DLVO) theory. ${ }^{8}$

The colloidal particles in a suspension seldom have a single, well-defined zeta potential. Most solid surfaces in water systems have heterogeneous zeta potential distributions. This charge heterogeneity is caused by complexity in the crystalline structure of the solids and their complex chemical composition. Surface-bound impurities may be an additional source of surface charge heterogeneity. ${ }^{4}$ Most experimental studies available in the literature are based on observed average mobilities of the particles; however, due to the variation of particle zeta potentials and the heterogeneous distribution of the collector surface charge, experiments in which the average surface potentials indicate conditions unfavorable to attachment can result in substantial amount of attachment, and vice versa. ${ }^{9}$

Electrokinetics is the general description applied to the four phenomena which arise when the mobile part of the EDL shears off from a charged surface. These four classical electrokinetic phenomena are as follows: streaming potential, sedimentation potential, electroosmosis, and particle electrophoresis. Among the four techniques, electrophoresis is the most commonly used for suspended colloidal particles, and streaming potential or electroosmosis are often used for coarse solid surfaces, such as mineral grains. ${ }^{4,6,8}$ During this research, electrophoresis was used.

Zeta potential can be approximated by electrophoretic mobility (EM), $U$, as shown in Equations 6 and 7.5

$$
\begin{gathered}
\zeta=\frac{U \mu}{\varepsilon_{w}} \\
\zeta=\frac{3 U \mu}{2 \varepsilon_{w}}
\end{gathered}
$$

where $\mu$ is the viscosity. $U$ has the same sign of the net surface charge of the particle and is negative if a particle moves toward a positively charged electrode. Equation 6 is referred to as the Smoluchowski equation and can be used when $\kappa a>>1$. On the other hand, when $\kappa a$ is a small value, then Hückel equation (Equation 7) can be used.

However, Equations 6 and 7 are approximations for extreme cases. When the external field is superimposed on the local field around the particle, then EM can be expressed for all values of $\kappa a$ as Equation $8 .{ }^{5}$

$$
U=\frac{2 \varepsilon_{w} \zeta}{3 \mu} f(\kappa a)
$$

where $f(\kappa a)$ is a correction function. $f(\kappa a)$ can have values between 1.0 and 1.5 depending on $\kappa a$ values. Ohshima has produced Equation 9 which gives a very good representation of the function $f(\kappa a)$ over the whole range of $\kappa a .{ }^{10}$

$$
f(\kappa a)=1+\frac{1}{2(1+\delta / \kappa a)}
$$

where $\delta$ is defined as $2.5 /\left(1+\mathrm{e}^{-\kappa a}\right)$. For particles that are large compared with the double layer thickness (i.e., $\kappa a>>$ 1), $f(\kappa a)$ can be regarded as 1.5 and then Equation 9 can be simplified to Equation 6. For particles that are quite small compared with the double layer thickness (i.e., $\kappa a<<1$ ), $f(\kappa a)$ can be regarded as 1.0 and then Equation 9 can be simplified to Equation 7. During this research, the Smoluchowski equation was used to calculate zeta potential from EM measurement because the value of $\kappa a$ was quite bigger than 1 .

The primary focus of this research was to investigate the characteristics of zeta potential distribution of silica particles under different chemical conditions.

\section{Experimental Methods}

Particles and Chemical Conditions. Min-U-Sil 5 (U.S. Silica Company, Berkeley Springs, WV) was used for particle material during this research. These particles are white, natural crystalline silica powders in the size range of 0.6 to $5.0 \mu \mathrm{m}$, and the manufacturer claims that Min-U-Sil 5 is at least $99.2 \% \mathrm{SiO}_{2}$. Figure 1 represents the particle size distribution (PSD) of Min-U-Sil 5 particles, where the majority of particles $(88.4 \%)$ have diameters in the range of 0.8 to $2.5 \mu \mathrm{m}\left(-0.1<\log d_{p}<0.4\right)$. PSD was measured by using Coulter Counter (Coulter Multisizer, Coulter Electronics Inc., Hialeah, FL).

To investigate the shape of Min-U-Sil 5, scanning electron microscopy (SEM) was performed using a Jeol T330A (Jeol USA Inc., Peabody, MA). SEM images reveal that these particles have an angular shape, as shown in Figure 2. On the other hand, Table 1 shows the properties of the Min-USil 5 that were used during this research.



Figure 1. Particle size distribution of Min-U-Sil 5 particles $(\mathrm{C}=$ $100 \mathrm{mg} / \mathrm{L})$. 


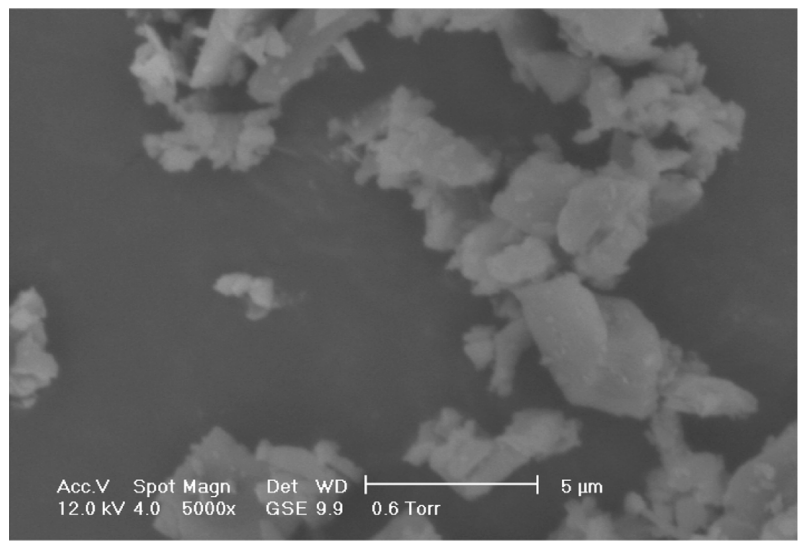

Figure 2. Scanning electron microscopy image of Min-U-Sil 5 particles.

Table 1. Properties of Min-U-Sil 5 particles (data provided by manufacturer)

\begin{tabular}{lc}
\hline Property & Value \\
\hline Particle size $(\mu \mathrm{m})$ & 5 \\
Nominal maximum size & $a$ \\
Median size & 1.7 \\
\hline Specific gravity & 2.65 \\
\hline $\mathrm{Chemical}$ analysis $(\%)$ & \\
$\mathrm{SiO}_{2}$ & 99.4 \\
$\mathrm{Fe}_{2} \mathrm{O}_{3}$ & 0.031 \\
$\mathrm{Al}_{2} \mathrm{O}_{3}$ & 0.26 \\
$\mathrm{TiO}_{2}$ & 0.01 \\
$\mathrm{CaO}$ & 0.01 \\
$\mathrm{MgO}$ & 0.02 \\
$\mathrm{Na}_{2} \mathrm{O}$ & 0.02 \\
$\mathrm{~K}_{2} \mathrm{O}$ & $<0.01$ \\
Loss on ignition & 0.3 \\
\hline
\end{tabular}

${ }^{a}$ Manufacturer reports $98 \%$ by weight below this size

In all experiments, the supply water was chemically conditioned depending on the specific objective of the experiment. Only distilled/deionized (Milli-Q water purification system, Millipore Corp., Bedford, MA) water was used throughout experiments. The Milli-Q water purification system consisted of activated carbon, ion exchange, and $0.22 \mu \mathrm{m}$ membrane cartridges. Min-U-Sil 5 was dispersed in Millipore water in order to make the particle suspension.

To investigate zeta potential distributions (ZPDs) under several different chemical conditions, three different particle destabilization methods were adopted: $\mathrm{pH}$ control, alum destabilization, and polymer destabilization.

Measurement of Zeta Potential. A number of techniques have been developed for electrophoresis: microscopic electrophoresis (microelectrophoresis), moving boundary electrophoresis, mass transport electrophoresis, tracer electrophoresis, and electrophoretic light scattering. Among these methods, microscopic electrophoresis has proven useful in the study of granular media filtration, and details on other methods are available elsewhere. ${ }^{1,6}$

The microscope method is used when the material has the form of a reasonably stable suspension or emulsion containing microscopically visible particles. In a classic instrument such as the Rank Brothers Mark II (Rank Brothers Ltd., U.K.), EM can be observed and measured directly. The particles are directly observed using this instrument, but its main disadvantage is related to the bias and subjectivity of the observer. ${ }^{1} \mathrm{~A}$ more recent instrument, such as the Zetaphoremeter IV (CAD, France), includes an automatic tracking function made possible by digital image processing. This instrument is simple to operate and it is easy to keep track of particles. The fundamental mechanisms of the recent instrument are identical to the classic instrument, with the exception that the recent instrument automatically tracks particles by using digital image analyzing software.

One of the major sources of error in electrophoresis is correctly locating the so-called stationary level. There are two stationary levels in the cell where the flow of liquid is zero, and the velocity of particles may be measured directly without interference from this liquid movement. The Komagate equation, shown in Equation 10, can be used to calculate the position of the stationary levels, $S_{L}$, for flat cells of finite width to depth ratios:

$$
\frac{S_{L}}{d}=0.500 \pm\left[0.0833+\frac{32 d}{\pi^{5} l}\right]^{1 / 2}
$$

where $d$ and $l$ are the cell thickness and width, respectively. ${ }^{5}$ During the research, every measurement was done only at the nearer of the two calculated stationary levels.

\section{Results and Discussion}

To investigate ZPDs under several different chemical conditions, three different particle destabilization methods were adopted: $\mathrm{pH}$ control, alum destabilization, and polymer destabilization. Filtration experiment results with respect to the ZPDs and PSDs of silica particles under the same chemical conditions can be found elsewhere. ${ }^{11}$

ZPD under pH Control. To find the zeta potential of Min-U-Sil 5 as a function of $\mathrm{pH}$ under constant ionic strength $\left(10^{-2} \mathrm{M} \mathrm{KCl}\right)$, several measurements of zeta

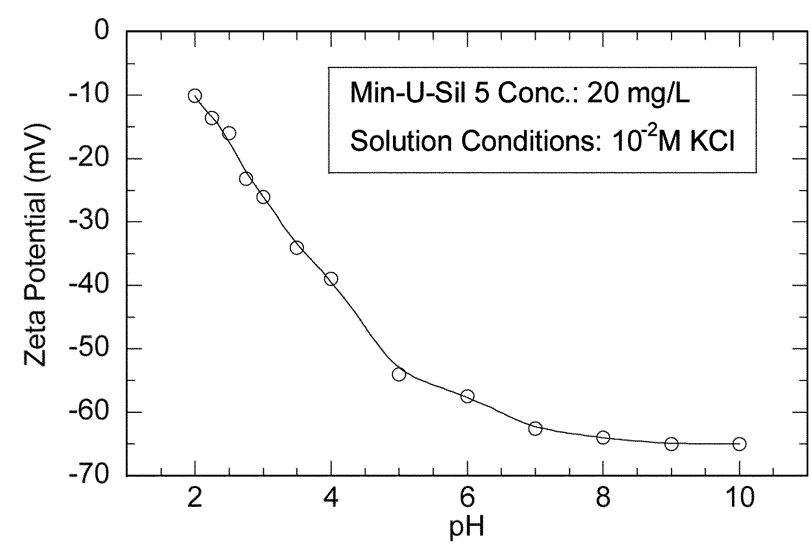

Figure 3. Mean zeta potential of Min-U-Sil 5: effect of $\mathrm{pH}$. 
Table 2. Summary of zeta potential measurements at three different $\mathrm{pH}$ values

\begin{tabular}{ccccc}
\hline $\mathrm{pH}$ & Mean zeta potential $(\mathrm{mV})$ & Number of particles measured & Standard deviation $(\mathrm{mV})$ & Coefficient of variation $(\%)$ \\
\hline 3.0 & -26.4 & 83 & 7.1 & 26.9 \\
4.0 & -38.7 & 138 & 9.2 & 23.8 \\
5.0 & -54.7 & 116 & 9.3 & 17.0 \\
\hline
\end{tabular}

potential were taken. The mean zeta potential of Min-U-Sil 5 particles at different $\mathrm{pH}$ conditions is shown in Figure 3, where mean zeta potentials were negative in the $\mathrm{pH}$ range between $\mathrm{pH} 2.0$ and 10.0. It was also noticed that the magnitude of mean zeta potentials of Min-U-Sil 5 were linearly proportional to the $\mathrm{pH}$ of the solution from $\mathrm{pH} 2.0$ to $\mathrm{pH} 5.0$ but reached fairly constant values at higher $\mathrm{pH}$.

Parks ${ }^{12}$ reported that the PZC of silica is between $\mathrm{pH} 2.0$ and 3.5, while Findlay et al. ${ }^{13}$ noticed that the PZC of MinU-Sil is below 2.0. Detailed test results on the zeta potential of Min-U-Sil 5 at a few selected $\mathrm{pH}$ values are presented in Table 2. During this research, the targeted total number of particles measured in the Zetaphoremeter was at least 80 , in order to have statistically significant counts. The standard deviations of the ZPD measurement during $\mathrm{pH}$ control ranged from 5 to $15 \mathrm{mV}$ (usually around $10 \mathrm{mV}$ ). The coefficient of variation was calculated as the standard deviation divided by

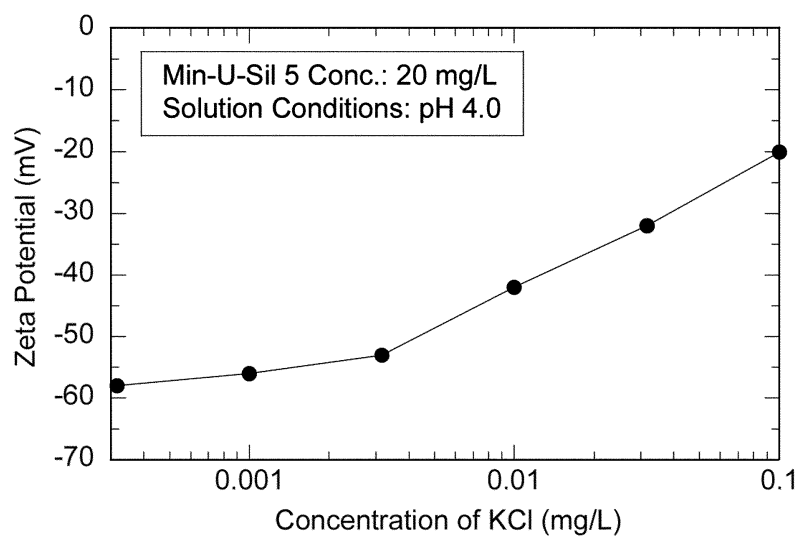

Figure 4. Mean zeta potential of Min-U-Sil 5: effect of ionic strength.

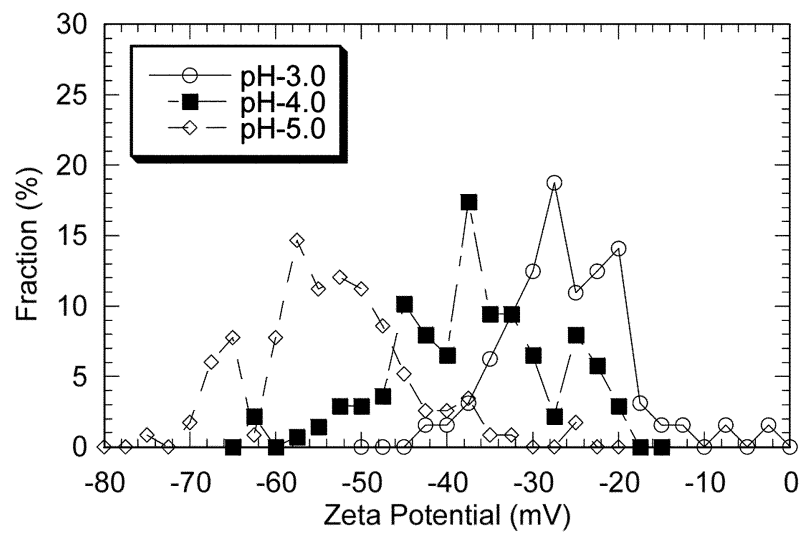

Figure 5. ZPDs of Min-U-Sil 5 at different $\mathrm{pH}$ values $\left(I=10^{-2} \mathrm{M}\right.$ $\mathrm{KCl})$. the absolute value of the mean value of the zeta potential.

The zeta potential of particles can also be changed by changing the ionic strength of a solution; an increase of ionic strength can compress the electric double layer, and thereby decrease the zeta potential. The mean zeta potential of MinU-Sil 5 at $\mathrm{pH} 4.0$ under different ionic strengths, controlled by varying the concentration of $\mathrm{KCl}$, is shown in Figure 4. This graph shows that a decrease of ionic strength can increase the absolute value of zeta potential, but this relationship was weak at lower ionic strength.

The ZPDs of Min-U-Sil 5 at the three influent $\mathrm{pH}$ conditions are shown in Figure 5. Those three different $\mathrm{pH}$ values were 3.0, 4.0 and 5.0, and the corresponding mean zeta potentials were $-26.4 \mathrm{mV},-38.7 \mathrm{mV}$, and $-54.7 \mathrm{mV}$ when Min-U-Sil 5 was dispersed in $10^{-2} \mathrm{M} \mathrm{KCl}$ solution.

ZPD under Alum Destabilization. One of the most popular destabilization methods applied in conventional water treatment plants is using an inorganic coagulant, such as aluminum sulfate (alum) or ferric sulfate that rapidly hydrolyzes to form insoluble precipitates and/or soluble polymers.

Amirtharajah and Mills ${ }^{14}$ noted that charge neutralization mechanisms are dominant in the $\mathrm{pH}$ range between 5.0 and 5.5 when alum is used as a coagulant. Therefore, $\mathrm{pH} 5.2$ was chosen during alum destabilization. Furthermore, to supply the proper buffer capacity and alkalinity, Min-U-Sil 5 particles were dispersed in $2 \times 10^{-3} \mathrm{M} \mathrm{NaHCO}_{3}$ throughout the alum destabilization experiments.

The mean zeta potential of Min-U-Sil 5 as a function of alum doses at $\mathrm{pH} 5.2$ is shown in Figure 6(A). The zeta potential of the Min-U-Sil 5 particles in a $20 \mathrm{mg} / \mathrm{L}$ suspension continuously increased (i.e., from negative to positive) with the increase of alum dose, from an initial value of $-70 \mathrm{mV}$ with $0.01 \mathrm{mg} / \mathrm{L}$ alum addition to $67 \mathrm{mV}$ at an alum dose of $5 \mathrm{mg} / \mathrm{L}$. The IEP of Min-U-Sil 5 was observed at an alum dose of approximately $0.6 \mathrm{mg} / \mathrm{L}$, when the influent solids concentration was $20 \mathrm{mg} / \mathrm{L}$. The zeta potential of Min-U-Sil 5 has a nearly linear relationship with the log of alum doses near the IEP, but this relationship was weaker at lower alum dose. The solids concentration remaining $\left(C / C_{o}\right)$ versus alum doses in the jar-tests is shown in Figure 6(B). As expected the solids concentration removal was better near the IEP. It can be thought that the attraction force was dominant at this point, leading to the best floc formation at the IEP.

A summary of zeta potential measurements at the three different alum doses is shown in Table 3, while the corresponding influent ZPDs are presented in Figure 7. These three different alum doses created three different chemical conditions, as well as different ZPDs. An alum dose of 0.2 $\mathrm{mg} / \mathrm{L}$ was considered the near optimum dose, while 0.06 $\mathrm{mg} / \mathrm{L}$ was below-optimum dose, and $0.8 \mathrm{mg} / \mathrm{L}$ corresponded 
Table 3. Summary of zeta potential measurements at three different alum doses

\begin{tabular}{ccccc}
\hline Alum dose $(\mathrm{mg} / \mathrm{L})$ & Mean zeta potential $(\mathrm{mV})$ & Number of particles measured & Standard deviation $(\mathrm{mV})$ & Coefficient of variation $(\%)$ \\
\hline 0.06 & -38.9 & 108 & 12.1 & 31.1 \\
0.2 & 7.9 & 166 & 12.2 & 154.4 \\
0.8 & 54.3 & 96 & 9.9 & 18.2 \\
\hline
\end{tabular}

to above-optimum dose. Particle size variation under different alum doses was not investigated during these experiments; further research is needed to understand the physical and
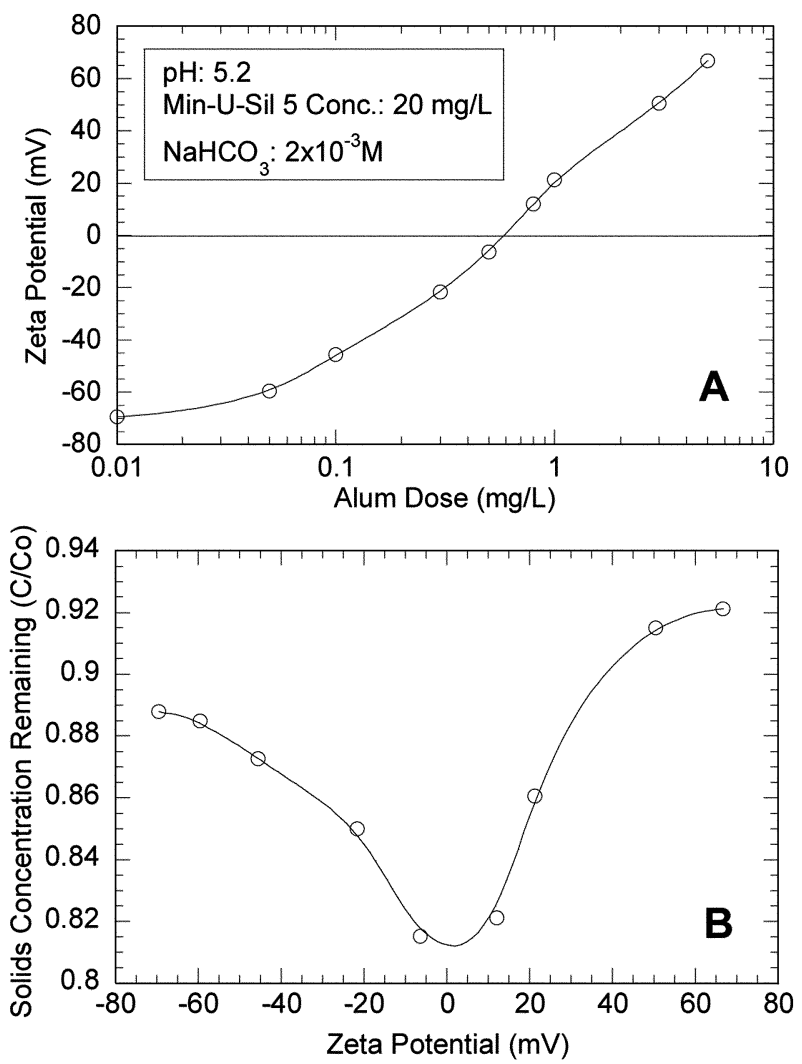

Figure 6. Effect of alum dose on mean surface charge (A) and effect of mean surface charge on coagulation (B).

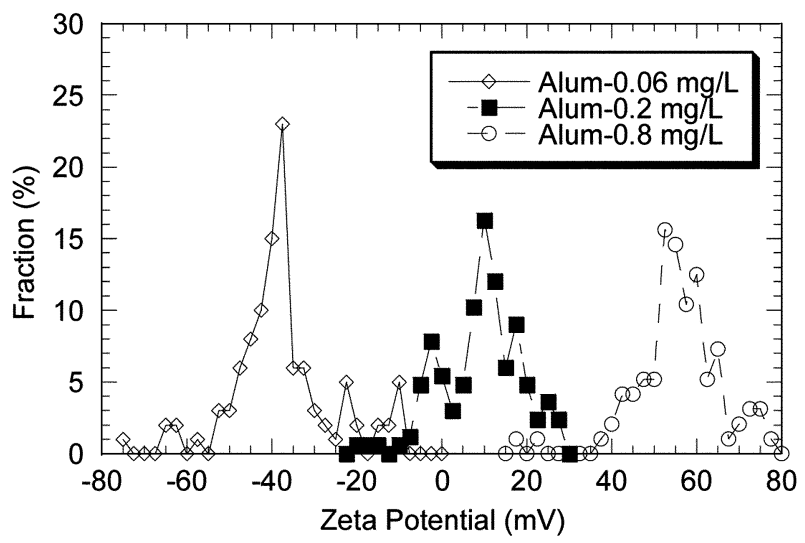

Figure 7. Zeta potential distributions of Min-U-Sil 5 at three different alum doses ( $\mathrm{pH}-5.2$ and Min-U-Sil 5 was dispersed in $2 \times$ $\left.10^{-3} \mathrm{M} \mathrm{NaHCO}_{3}\right)$. chemical properties before and after the particles are agglomerated.

During the alum destabilization, one concern is whether the mean zeta potential of particles is a function of particle concentration. When the charge neutralization mechanism is adopted, the amount of needed positive charge, i.e., the amount of coagulant, can be assumed to be proportional to the total surface area of particles in the suspension. ${ }^{7}$ This idea is confirmed in the results shown in Figure 8.

ZPD under Polymer Destabilization. Several types of polymers are widely used in particle removal processes at WTPs, depending on the specific purpose of polymer addition (e.g., primary coagulant, coagulant aid, and filter aid). A high-charge-density cationic polymer is often used as a primary coagulant because of its high potential for charge neutralization, whereas a high-molecular-weight nonionic, anionic, and low-charge density cationic polymer is usually used as a coagulant aid because of its bridging capabilities. ${ }^{7}$

As polymer was considered as a primary coagulant (for direct filtration) during this research, high-charge-density cationic polymers such as poly-DADMAC and polyamine, were considered as possible coagulants. Physical characteristics of these two polymer coagulants are presented in Table 4. During this research, the main mechanism of polymer destabilization was charge neutralization; thus a polymer that has a relatively low molecular weight was chosen to minimize the bridging effect during the filtration. Therefore, polyamine (Superfloc C-572, Cytec Industries Inc., IN) was used for this research.

Water chemistry during the polymer destabilization experiment was the same as with alum destabilization: the $\mathrm{pH}$ was 5.2 , and the supply water was buffered with $2 \times 10^{-3} \mathrm{M}$ $\mathrm{NaHCO}_{3}$.

Based on the jar-test results, three different polymer doses were chosen to make negative, near zero, and positive particle surface charges. Those three doses were $0.001 \mathrm{mg} / \mathrm{L}$ (below-optimum dose), $0.01 \mathrm{mg} / \mathrm{L}$ (optimum dose), and 0.1 $\mathrm{mg} / \mathrm{L}$ (above-optimum dose), and the corresponding mean

Table 4. Characteristics of polymers used during this research (data provided by manufacturer)

\begin{tabular}{lcc}
\hline Products & C-572 & C-587 \\
\hline Type & Polyamine & polyDADMAC \\
Appearance & Liquid & Liquid \\
Charge & Cationic & Cationic \\
Relative molecular weight & Very low & Medium \\
Specific gravity $\left(25^{\circ} \mathrm{C}\right)$ & $1.14-1.18$ & $1.01-1.05$ \\
$\%$ Solid & $49.0-51.0$ & $19.0 \mathrm{Min}$ \\
$\mathrm{pH}$ & $5.0-7.0$ & $5.0-8.0$ \\
Bulk viscosity $\left(25^{\circ} \mathrm{C}, \mathrm{cps}\right)$ & $80-125$ & $300 \mathrm{Max}$ \\
\hline
\end{tabular}




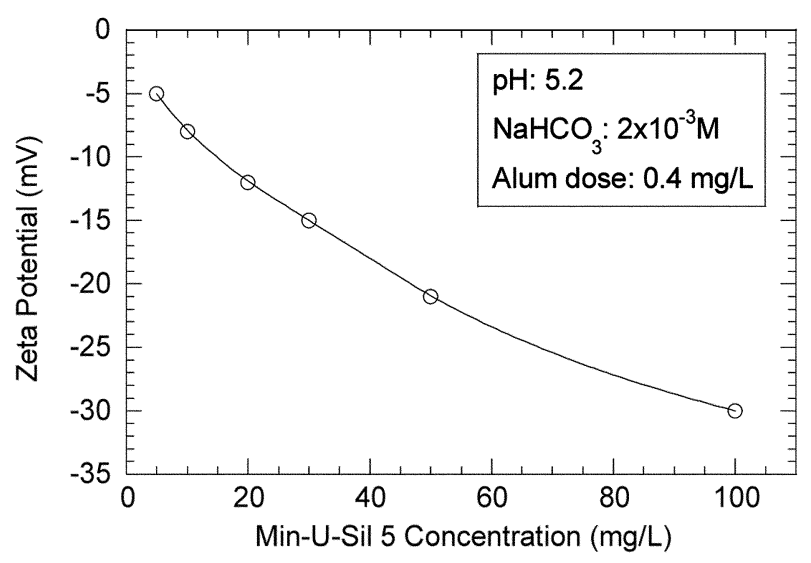

Figure 8. Mean zeta potential of Min-U-Sil 5 as a function of sol concentration at alum dose of $0.4 \mathrm{mg} / \mathrm{L}$.

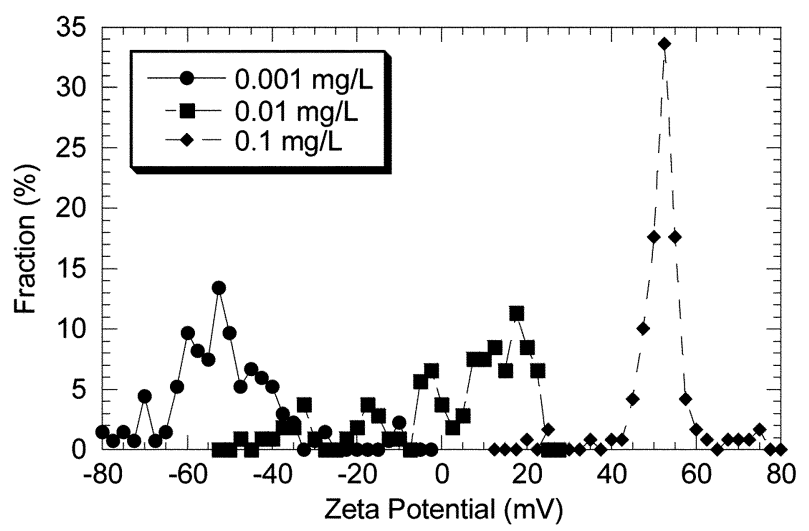

Figure 9. Zeta potential distributions of Min-U-Sil 5 at three different polymer doses (pH-5.2 and Min-U-Sil 5 was dispersed in $\left.2 \times 10^{-3} \mathrm{M} \mathrm{NaHCO}_{3}\right)$.

zeta potentials were $-53.3 \mathrm{mV}, 1.0 \mathrm{mV}$, and $50.9 \mathrm{mV}$. Influent ZPDs at the three different polymer doses are shown in Figure 9. One of the characteristics of this graph is that the standard deviation at the above-optimum dose was relatively narrow, while that of the optimum dose was wide. This result was not investigated during the $\mathrm{pH}$ change and alum addition experiments. The reason why this occurred is unclear, but it can be assumed to be related to the polymer's high surface charge density. A summary of zeta potential measurements at the three different polymer doses is presented in Table 5.

As previously noticed during the alum destabilization, the ZPD of particles at a given coagulant dose was also a function of the particle concentration. The mean zeta potential at different Min-U-Sil 5 concentrations at polymer dose of $0.01 \mathrm{mg} / \mathrm{L}$ is shown in Figure 10. One of the big differences

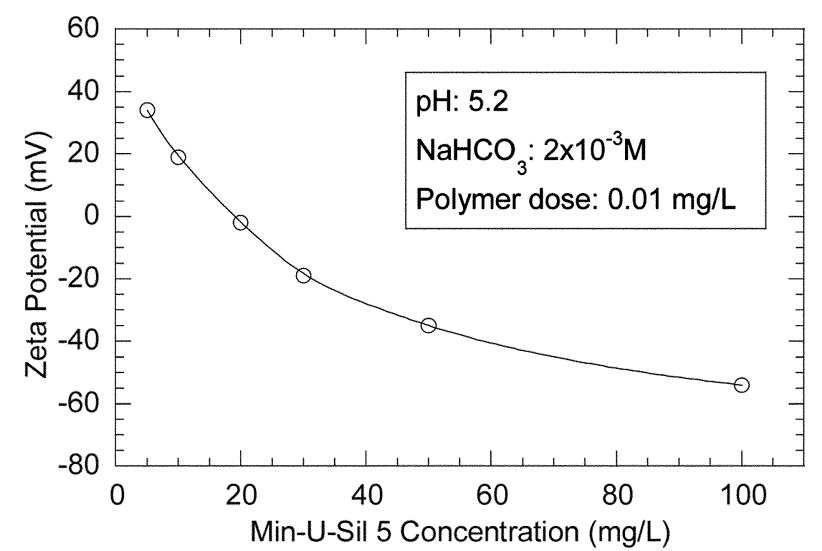

Figure 10. Mean zeta potential of Min-U-Sil 5 as a function of solids concentration at polymer dose of $0.01 \mathrm{mg} / \mathrm{L}$.

between polymer and alum destabilization is that with polymer destabilization, the surface charge of Min-U-Sil 5 was more strongly a function of solids concentration. When alum was used, the mean zeta potential was changed from $-30 \mathrm{mV}$ to $-5 \mathrm{mV}$, i.e., a net change of $25 \mathrm{mV}$; on the other hand, when polymer was used, it was changed from $-54 \mathrm{mV}$ to $34 \mathrm{mV}$, i.e., a net change of $88 \mathrm{mV}$ under the same conditions: the solids concentration varied from $5 \mathrm{mg} / \mathrm{L}$ to $100 \mathrm{mg} / \mathrm{L}$, the supply water was buffered to $2 \times 10^{-3} \mathrm{M}$ $\mathrm{NaHCO}_{3}$, and the $\mathrm{pH}$ was 5.2 .

\section{Summary and Conclusions}

The major observations based on zeta potential measurements of silica particles under three different destabilization methods ( $\mathrm{pH}$ control, alum destabilization and polymer destabilization) are stated below.

1. Contrary to most researchers' assumptions, the majority of ZPDs for silica particles were broad. Therefore, experiments in which the average surface potentials indicate conditions unfavorable to attachment can still result in substantial amounts of attachment because of the variation of particle zeta potentials and the heterogeneous distribution of the collector surface charge, and vice versa.

2. The mean zeta potential of silica particles at a given coagulant dose was a function of particle concentration; the amount of needed coagulant for particle destabilization was proportional to the total surface charge area of particles in the suspension.

3. The solids concentration removal was better near the IEP. It can be thought that the attraction force was dominant at this point, leading to the best floc formation at the IEP.

4. The zeta potential of particles can be changed by

Table 5. Summary of zeta potential measurements at three different polymer doses

\begin{tabular}{ccccc}
\hline Polymer dose $(\mathrm{mg} / \mathrm{L})$ & Mean zeta potential $(\mathrm{mV})$ & Number of particles measured & Standard deviation $(\mathrm{mV})$ & Coefficient of variation $(\%)$ \\
\hline 0.001 & -53.3 & 134 & 13.1 & 24.6 \\
0.01 & 1.0 & 106 & 18.1 & 1810.0 \\
0.1 & 50.9 & 119 & 7.9 & 15.5 \\
\hline
\end{tabular}


changing the ionic strength of a solution. An increase of ionic strength can compress the electric double layer, and thereby decrease the zeta potential while a decrease of ionic strength can increase the zeta potential.

\section{References}

1. Delgado, A. V.; Arroyo, F. J. Interfacial Electrokinetics and Electrophoresis; Marcel Dekker, Inc.: New York, 2002; p 25.

2. Stumm, W.; Morgan, J. J. Aquatic Chemistry, $3^{\text {rd }}$ Ed.; WileyInterscience: New York, 1996; pp 516-586.

3. Edzwald, J. K. Treatment Process for Particle Removal; AWWARF and AWWA: Denver, 1997; pp 73-87.

4. Elimelech, M.; Gregory, J.; Jia, X.; Williams, R. Particle Deposition and Aggregation; Butterworth Heinemann: Oxford, U.K., 1995; pp 23-32.

5. Hunter, R. J. Foundations of Colloid Science, $2^{\text {nd }}$ Ed.; Oxford
University Press Inc.: New York, 2001; pp 373-433.

6. Shaw, D. J. Introduction to Colloid and Surface Chemistry; Butterworth-Heinemann Ltd.: England, 1992; pp 189-209.

7. Letterman, R. D. Water Quality and Treatment, $5^{\text {th }}$ Ed.; McGrawHill: New York, 1999; pp 6.1-6.43.

8. Elimelech, M.; Nagai, M.; Ko, C.; Ryan, J. N. Environmental Science and Technology 2000, 34(11), 2143-2148.

9. Rajagopalan, R.; Chu, R. Q. J. of Colloid and Interface Science 1982, 86(2), 299-317.

10. Ohshima, H. J. of Colloid and Interface Science 1994, 168(1), 269-271.

11. Kim, J. Physicochemical Aspects of Particle Breakthrough in Granular Media Filtration, Ph.D. Dissertation; The University of Texas at Austin: 2004; pp 125-225.

12. Parks, G. A. Chemical Reviews 1965, 65, 177-198.

13. Findlay, A. D.; Thompson, D. W.; Tipping, E. Colloids and Surfaces A: Physicochemical and Engineering Aspects 1996, 118(1,2), 97-105.

14. Amirtharajah, A.; Mills, K. M. J. AWWA 1982, 74(4), 210-216. 